\title{
NUCLEAR MORPHOMETRY IN AFRICAN BREAST CANCER
}

\author{
OFFIONG FRANCIS IKPATT ${ }^{1}$, TEIJO KUOPIO ${ }^{2}$ AND YRJÖ COLLAN ${ }^{3}$ \\ ${ }^{1}$ Department of Pathology, University of Calabar Teaching Hospital, Nigeria, ${ }^{2}$ Department of Pathology, \\ JyväkyläCentral Hospital, Finland, ${ }^{3}$ Department of Pathology, University of Turku, Finland \\ e-mail: ofrikpatt@yahoo.com \\ (Accepted January 14, 2002)
}

\begin{abstract}
Three hundred cases of invasive breast cancer diagnosed between 1983 and 1999 in Calabar, Nigeria were analysed to determine the nuclear morphometric variables, and evaluate the prognostic potential of nuclear morphometry in Nigerian breast cancers. The necessary follow-up was available for 129 patients. The nuclear area was the most valuable variable. In the Nigerian material, the mean nuclear area (MNA) (SD) was 89.2 (34.0) $\mu^{2}$. MNA was significantly higher in tumours of the postmenopausal than premenopausal $(\mathrm{p}=0.0405)$, in $\mathrm{LN}+$ than $\mathrm{LN}-(\mathrm{p}=0.0202)$ patients, and in tumours over $3 \mathrm{~cm}$ than smaller ones $(\mathrm{p}<0.0001)$. There were also significant differences between different clinical stages, histological grades, and histological types of tumours. Significant correlations were observed between MNA and histological grade $(\mathrm{r}=0.64)$, standard mitotic index $(\mathrm{r}=0.45)$ and tumour size $(\mathrm{r}=0.20)$. MNA as a continuous variable was a statistically significant prognosticator in the whole material $(\mathrm{p}=0.0281)$, and among the postmenopausal patients $(\mathrm{p}=0.0238)$. Univariate cox's regression demonstrated one significant grading cutpoint at MNA $=111 \mu \mathrm{m}^{2}$, which divided the material into two groups of different survival. The development of a morphometric grading system optimal for the Nigerian material could use the latter cut-point between nuclear scores 2 and 3 in the grading system. The earlier proven cut-point of $47 \mu \mathrm{m}^{2}$ could be used between nuclear scores 1 and 2.
\end{abstract}

Keywords: Africa, breast cancer, morphometry, nuclear area, prognostication.

\section{INTRODUCTION}

Significant clinical and histological differences between Nigerian and European breast cancers have been reported (Ihekwaba, 1992; Oluwole et al., 1987; Ikpatt et al., 2001). The differences also include nuclear features, like greater variations in nuclear sizes and shapes of Nigerian tumours. Nuclear morphometric parameters can identify an aggressive tumour phenotype and provide additional prognostic information for patients with invasive breast cancer (Chiusa et al., 2000; Tahlan et al., 2000; Jalava et al., 2001).

Because differences exist between breast cancer populations, the development of a morphometric grading system in Nigeria could be based on different diagnostic and grading cut-points than those applicable to European materials (Kronqvist et al., 1998). In this study, we have tested this hypothesis.

\section{MATERIAL AND METHODS}

\section{PATIENT MATERIAL}

The characteristics of the patients are shown in Table 1.

Three hundred (300) patients with invasive breast carcinoma seen at the University of Calabar Teaching Hospital, Nigeria, between and 1983 and 1999 were studied (Ikpatt et al., 2001). None of the patients had preoperative radiotherapy or any other form of adjuvant treatment. All were treated with either simple or radical mastectomy with axillary evacuation. Chemotherapy was given after surgery to $85(65.9 \%)$. Twenty (15.5\%) had endocrine therapy while 19 (6.3\%) had both chemotherapy and endocrine therapy. Twenty-four (18.6\%) had additional radiotherapy to the surgery. Follow- up information was obtained from 
the hospital medical records. Follow- up history was available for 129 patients and the mean follow-up period was 25.9 months.

The end point of the follow-up was the survival status, which keenly followed the pattern of disease recurrence. Deaths from other causes than cancer were recorded when information was available, and only cancer-associated survival was evaluated as end point in the survival analysis.

Table 1. Clinical characteristics of the 300 studied Nigerian patients and their breast cancers.

\begin{tabular}{lr}
\hline AGE AT DIAGNOSIS (years) & \\
\hline Mean (SD) & $42.7(12.1)$ \\
Median & 41 \\
Range & $18-85$ \\
\hline MENOPAUSAL STATUS & $223(74.3 \%)$ \\
\hline No of premenopausal patients & $77(25.7 \%)$ \\
\hline Postmenopausal patients & \\
\hline AXILLARY LYMPH NODE STATUS & \\
\hline No of positive patients & \\
No of negative patients & $64(21.3 \%)$ \\
\hline TuMOUR SIZE (cm) & \\
\hline Mean (S.D.) & \\
Median & 2.8 .3 \\
Range & $2.0-60$ \\
\hline FolLOW-UP TIME (months) & \\
\hline Mean (SD) & 92.11 .0 \\
Range & $(71.3 \%)$ \\
\hline Alive after follow-up & \\
\hline CAUSES OF DEATH DURING FOLLOW-UP & \\
\hline Breast cancer & \\
Other & \\
\hline
\end{tabular}

\section{HISTOLOGIC EXAMINATION AND MORPHOMETRIC METHOD}

All the samples were fixed in buffered formalin and embedded in paraffin. Sections were cut at $5 \mu \mathrm{m}$ and stained with haematoxylin and eosin. The histologic typing (WHO, 1981) and grading (Bloom and Richardson, 1957) were done by one of the authors (OFR). An agreement was reached after pair reviewing the unclear cases with a co-author (YC).

The nuclear profile (Kronqvist et al., 1997; 1998) of the samples were measured using a digitising interactive image overlay system run by the Prodit morphometry program (Prodit 3.1, Promis Inc, Almere, The Netherlands). The system includes a microscope, a personal computer (MultiSync 3D Color Monitor; NEC, Japan), a video camera (JVC TK-870U; JVC Japan) and a digitizer board (PIP512B video digitizer board; Matrox Electronic Systems, Dorval, Quebec, Canada). Digitised images of the nuclear profile were outlined on the monitor screen using a computer mouse. The instrument was calibrated with a micrometer slide before each measurement. Measurement were carried at out at $\times 2500$ magnification on the monitor screen $(\times 40$ objective magnification, $\times 10$ video ocular and $\times 2$ internal magnification). In the measurement, the most cellular area, usually at the periphery of the tumour, was looked for. Necrotic and inflammatory areas were avoided. An average of 8-15 microscopic fields were screened and 50 consecutive tumour cells with clear nuclear borders were outlined with the computer mouse. Overlapping nuclei were not measured. At the end of each measurement, the computer automatically produced the basic statistics of the variables. Measurement was carried out by one of the authors after a period of training (Kronqvist et al., 1997).

\section{Data analysis}

The discrete variables of the material were grouped into logical classes and descriptive statistics calculated for the continuous variables using SAS statistical package (SAS System for Windows release 6.12 SAS Institute Inc., Cary, NC).

For survival analysis, Kaplan-Meier curves (Cutler and Ederer,1958) were plotted, and differences between the curves analysed using the log-rank test. The nuclear morphometric thresholds were the cutoff points showing curve separation with the highest statistical significance.

Univariate and multivariate analyses were performed with the Cox's regression model to evaluate additional prognostic value of the nuclear profile to other prognostic variables. The ratios indicating relative risk (RR) and their $95 \%$ confidence intervals $(95 \% \mathrm{CI})$ showed associations between different prognostic factors and breast cancer survival.

P-values below 0.05 were regarded as significant. Student t-tests and ANOVA were also used to test differences between the groups.

\section{RESULTS}

The characteristics of the patients are shown in Table 1.

In the whole material, the mean nuclear area (SD) and diameter (SD) were 89.2(34.0) $\mu \mathrm{m}^{2}$ and 10.3(2.0) $\mu \mathrm{m}$, respectively. The nuclear measurements were significantly higher in tumours of the postmenopausal than premenopausal patients (nuclear area, $\mathrm{p}=0.0405$ ). The values were also higher in lymph node-positive patients than lymph node-negative ones (nuclear area, 
$\mathrm{p}=0.0202$ ) and in larger tumours (nuclear area, $\mathrm{p}<0.0001$ ), (Table 2).

Values of morphometric nuclear variables in the Nigerian material according to the clinical stage, histologic grade, histologic types are shown in Table 3. Increasing clinical stage and histologic grade was accompanied by increasing values of the mean nuclear area. The differences in nuclear area between stages 1 and $4(p=0.0100)$, IDC and other histological types $(p=0.0011)$, and grades 1 and 3 were statistically significant. The differences between grades were verified by ANOVA $(\mathrm{p}<0.0001)$.

Significant associations were observed between the tumour nuclear area and the histologic grade $(\mathrm{r}=$ $0.64)$, standard mitotic index $(\mathrm{r}=0.45)$, mitotic activity index $(r=0.51)$, extent of necrosis $(r=0.33)$, tumour size $(r=0.20)$ and clinical stage $(r=0.18)$. A significant negative correlation was observed with the fraction of tubular differentiation $(\mathrm{r}=-0.47)$.

Of the 129 invasive breast cancers available for follow-up, 108 (83.7\%) were invasive ductal carcinoma.

Of all the various nuclear parameters, the nuclear area consistently turned out to be the most valuable prognosticator. The statistical significance of this feature, studied as a continuous variable, was evident when studied in the whole material (clinical stages 1-4) $(p=0.0281)$. In this material, nuclear area was a significant prognostic variable among postmenopausal patients $(\mathrm{p}=0.0238)$, and almost significant among $\mathrm{LN}+$ patients $(\mathrm{p}=0.0527)$. Significant association could not be demonstrated among $\mathrm{LN}$ - and premenopausal patients, among tumours $\leq 5 \mathrm{~cm}$ or $>5 \mathrm{~cm}$, or among groups formed by different grades or clinical stages.

Table 2. Means of morphometric nuclear variables $(S D)$ in the Nigerian material $(n=300)$ and according to subgroups divided by menopausal status, lymph node status and tumour size.

\begin{tabular}{lcccccc}
\hline & $\begin{array}{c}\text { Area } \\
\left(\mu \mathrm{m}^{2}\right)\end{array}$ & $\begin{array}{c}\text { Diameter } \\
(\mu \mathrm{m})\end{array}$ & $\begin{array}{c}\text { Perimeter } \\
(\mu \mathrm{m})\end{array}$ & $\begin{array}{c}\text { Longest axis } \\
(\mu \mathrm{m})\end{array}$ & $\begin{array}{c}\text { Shortest axis } \\
(\mu \mathrm{m})\end{array}$ & $\begin{array}{c}\text { SD Area } \\
\left(\mu \mathrm{m}^{2}\right)\end{array}$ \\
\hline Whole material & $89.2(34.0)$ & $10.3(2.0)$ & $34.4(6.8)$ & $13.1(2.6)$ & $8.5(2.8)$ & $28.4(14.3)$ \\
\hline Menopausal status *p $=0.0405$ & & & & & & \\
Premenopausal & $86.8(33.7)$ & $10.2(2.0)$ & $33.9(6.8)$ & $12.9(2.6)$ & $8.5(2.8)$ & $27.2(14.0)$ \\
Postmenopausal & $96.0(34.2)$ & $10.7(1.9)$ & $36.0(6.7)$ & $13.6(2.6)$ & $8.8(1.7)$ & $31.7(14.9)$ \\
\hline Lymph node (LN) status $\mathrm{p}=0.0202$ & & & & & \\
LN+ & $91.6(34.2)$ & $10.5(2.0)$ & $34.9(6.7)$ & $13.2(2.6)$ & $8.7(1.7)$ & $29.0(14.1)$ \\
LN- & $80.5(31.9)$ & $9.8(1.9)$ & $32.8(6.6)$ & $12.4(2.6)$ & $8.1(1.6)$ & $25.9(15.1)$ \\
\hline Tumour size $\mathrm{p}<0.0001$ & & & & & \\
$<3 \mathrm{~cm}$ & $77.1(31.8)$ & $9.6(1.9)$ & $32.1(6.6)$ & $12.2(2.6)$ & $8.0(1.6)$ & $24.9(14.5)$ \\
$>3 \mathrm{~cm}$ & $94.3(33.7)$ & $10.7(1.9)$ & $35.4(6.6)$ & $13.4(2.5)$ & $8.8(1.6)$ & $29.8(14.0)$ \\
\hline
\end{tabular}

*Student's t-test p-values comparing the mean nuclear areas of different classes in subgroups.

Table 3. Means of morphometric nuclear variables $(S D)$ in the Nigerian material $(n=300)$ according to the clinical stage, histologic grade and histologic type.

\begin{tabular}{lcccccc}
\hline & $\begin{array}{c}\text { Area } \\
\left(\mu \mathrm{m}^{2}\right)\end{array}$ & $\begin{array}{c}\text { Diameter } \\
(\mu \mathrm{m})\end{array}$ & $\begin{array}{c}\text { Perimeter } \\
(\mu \mathrm{m})\end{array}$ & $\begin{array}{c}\text { Longest axis } \\
(\mu \mathrm{m})\end{array}$ & $\begin{array}{c}\text { Shortest axis } \\
(\mu \mathrm{m})\end{array}$ & $\begin{array}{c}\text { SD Area } \\
\left(\mu \mathrm{m}^{2}\right)\end{array}$ \\
\hline Clinical stage & $* \mathrm{p}=0.0100$ & & & & & \\
Stage 1 & $80.5(31.9)$ & $9.8(1.9)$ & $32.8(6.6)$ & $12.4(2.6)$ & $8.1(1.6)$ & $25.9(15.1)$ \\
Stage 2 & $83.8(32.9)$ & $10.0(2.0)$ & $33.5(6.5)$ & $12.7(2.6)$ & $8.3(1.6)$ & $25.4(12.9)$ \\
Stage 3 & $98.1(32.7)$ & $10.7(1.9)$ & $35.3(6.8)$ & $13.5(2.5)$ & $8.8(1.6)$ & $31.2(14.3)$ \\
Stage 4 & $96.0(37.0)$ & $10.7(2.1)$ & $35.7(6.9)$ & $13.5(2.6)$ & $8.9(1.8)$ & $30.1(14.4)$ \\
\hline Histologic grade & $* * \mathrm{p}<0.0001$ & & & & & \\
Grade 1 & $53.3(21.7)$ & $8.1(1.5)$ & $26.7(4.9)$ & $10.0(2.0)$ & $6.8(1.1)$ & $16.6(10.1)$ \\
Grade 2 & $76.8(20.7)$ & $9.7(1.3)$ & $32.5(4.4)$ & $12.4(1.9)$ & $8.0(1.1)$ & $23.2(10.1)$ \\
Grade 3 & $111.4(31.1)$ & $11.6(1.7)$ & $38.6(6.1)$ & $14.6(2.1)$ & $9.6(1.5)$ & $36.6(13.9)$ \\
\hline Histologic type & $* * * \mathrm{p}=0.0011$ & & & & & \\
IDC (242) & $94.3(32.5)$ & $10.7(1.8)$ & $35.5(6.3)$ & $13.5(2.4)$ & $8.8(1.6)$ & $30.1(14.2)$ \\
Lobular (10) & $60.1(17.2)$ & $8.6(1.4)$ & $28.9(4.7)$ & $10.9(2.1)$ & $7.1(0.9)$ & $18.3(9.3)$ \\
Others (48) & $69.5(33.9)$ & $9.1(2.1)$ & $30.3(7.4)$ & $11.4(2.9)$ & $7.6(1.7)$ & $22.3(13.6)$ \\
\hline
\end{tabular}

*ANOVA was used to test differences between the groups.

** Student's t-test p-values comparing the mean nuclear areas of grade 1 and 3 tumours.

*** Student's t-test p-values comparing the mean nuclear areas of IDC and other histological types. 
Univariate analysis of the material for a possible decision cut-point showed a statistically significant nuclear area threshold of $111 \mu \mathrm{m}^{2}$. This value appeared useful in the whole Nigerian material $(\mathrm{p}=0.0155)$, postmenopausal patients $(\mathrm{p}=0.0168)$, and $\mathrm{LN}+$ subgroup (0.0239). The prognostic effect of MNA was lost when stages 1-3 only were studied. Table 4 shows the univariate analysis for the significance of the nuclear area as a prognosticator in the Nigerian material. The value of the nuclear area as a prognostic variable is demonstrated in Fig. 1 at the cut-point of $111 \mu \mathrm{m}^{2}$.

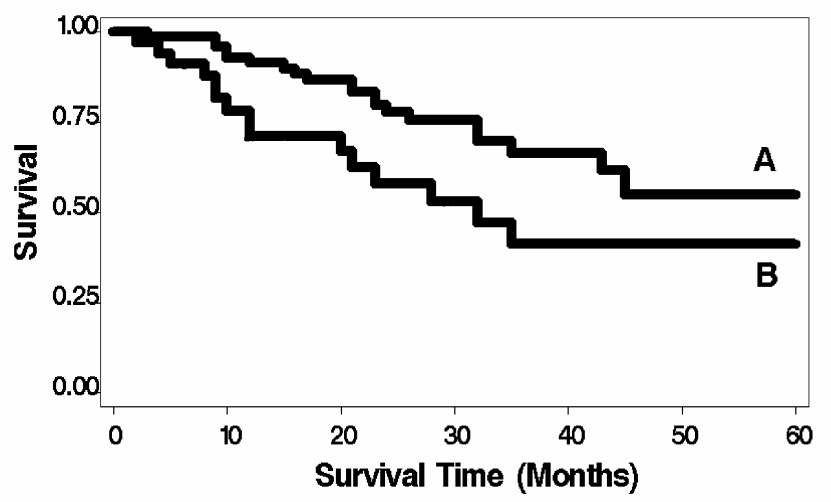

Fig. 1. Survival of 129 patients, of which follow-up was available, with infiltrating breast carcinoma divided by mean nuclear area (MNA). Patients had tumours in stages 1-4. The survival difference is statistically significant (log-rank $p<0.027)$. Curve A: Patients with MNA equal or lower than $111 \mu^{2}$. Curve B: Patients with MNA above $111 \mathrm{\mu m}^{2}$.

\section{DISCUSSION}

This study is a part of our objectives at obtaining a morphometric grading system specifically suitable for Nigerian breast cancers. The nuclear morphometry has shown prognostic significance in numerous studies (Baak et al., 1985; Kronqvist et al., 1998; Parada et al., 1999).

The mean nuclear area (SD) of $89.2(34.0) \mu \mathrm{m}^{2}$ seen in Nigeria was significantly higher than the 38.6(15.0) $\mu \mathrm{m}^{2}$ observed in Finnish material (Kronqvist et al., 1998) and 24.4(12.8) to 67.8(18.4) $\mu \mathrm{m}^{2}$ in other European (Baak, 1985; 1992; Ladekarl and Söensen, 1993) studies. One explanation for the difference may be that the European materials only presented clinical stages 1-3. Also the distribution of grades varies between Nigerian and European materials, grade 3 being especially common in Nigeria, which could affect the mean values. However, also the technique may have affected the results because only non-overlapping nuclei were measured.

There is a gradual increase in the mean nuclear area (MNA) from baseline value of normal breast epithelium through benign diseases to invasive cancers (Skjorten et al., 1991; Ruiz et al., 1999). The baseline MNA value of normal breast epithelium in African and European populations may differ, although this is not probable.

To ensure reproducibility, a random measurement of some previously assessed Finnish samples had yielded comparable values to that obtained by Kronqvist et al. (1998). The high MNA values observed in the Nigerian material may reflect actual biological differences between breast cancers in the 2 populations. Earlier studies have shown a more extensive nuclear atypia, with occasional giant cells, in Nigerian breast cancer (Ikpatt et al., 2001). A comparably high value of MNA $\left(72.1 \mu \mathrm{m}^{2}\right)$ was observed in Asian breast cancers in which tumours of large size, high nuclear grade and comedo histological pattern predominated (Tan et al., 2001).

Table 4. Univariate analysis on the significance of the nuclear area as a prognosticator in the whole Nigerian material (number of patients with follow-up =129) using the nuclear area as a continuous variable, and at the threshold of $111 \mathrm{\mu m}^{2}$, respectively. Different subgroups of the whole material are also tested in the corresponding fashion.

\begin{tabular}{lllll}
\hline Group of patient & $\begin{array}{l}\text { Prognostic } \\
\text { feature }\end{array}$ & $\mathrm{P}$ & $\begin{array}{l}\text { Risk ratio } \\
(\mathrm{RR})\end{array}$ & $95 \% \mathrm{CI}^{*}$ \\
\hline All & continuous variable & 0.0281 & 1.0 & $0.9-1.1$ \\
$(\mathrm{n}=129)$ & cut-point 111 & 0.0155 & 2.3 & $1.2-4.3$ \\
\hline Premenopausal & continuous variable & 0.3409 & 1.0 & $0.9-1.1$ \\
$(=97)$ & cut-point 111 & 0.2494 & 1.6 & $0.7-3.8$ \\
\hline Postmenopausal & continuous variable & 0.0238 & 1.0 & $0.9-1.1$ \\
$(=32)$ & cut-point 111 & 0.0168 & 4.2 & $1.3-13.7$ \\
\hline Node positive & continuous variable & 0.0527 & 1.0 & $1.0-1.1$ \\
$(=76)$ & cut-point 111 & 0.0239 & 2.2 & $1.1-4.2$ \\
\hline
\end{tabular}

$* \mathrm{CI}=$ confidence interval 
Significant association between nuclear grade, cell proliferation and nuclear morphometric parameters exist (Baak, 1985; 1992; Ladekarl and Söensen, 1993). This was equally observed in our study. We had earlier observed significantly higher proliferative activity in the Nigerian than the Finnish material (Ikpatt et al., 2001). The higher MNA, therefore, can be expected to reflect the increased proliferation in Nigerian breast cancer. This view is further substantiated by the study of Gläkner (2001) who showed that the amplification and increased expression of erbB2 (growth factor receptor associated with increased growth rate) is associated with higher nuclear grade in intraductal cancers.

As a prognosticator the MNA is clearly weaker than the mitotic counts, and this is true both for the Finnish and Nigerian materials (Kronqvist et al., 1998b; Ikpatt et al., 2001). The significance of the morphometric values, however, was clearly different from the Finnish experience. In Nigeria, MNA was of prognostic value in the whole material (stage 1-4), and in the subgroups of $\mathrm{LN}+$ and postmenopausal patients. It had a restricted value in the premenopausal patients. On the other hand, MNA was useful in the premenopausal patients in European based studies (Baak et al.,1993; Kronqvist et al., 1998).

For grading purposes, we could demonstrated only one significant threshold at the end of the scale $\left(111 \mu \mathrm{m}^{2}\right)$ in the Nigerian material. Kronqvist et al. (1998) observed two cut-points (32 and $47 \mu \mathrm{m}^{2}$ ) in the Finnish material. The findings seem to suggest that the most efficient grading system, involving a nuclear pleomorphism score on a linear analogue scale of 1-3, in Nigeria may not be the same as in Europe, because the average nuclear sizes are larger in the Nigerian material. In fact our results suggest that the cut-point between nuclear scores 2 and 3 should be placed at $111 \mu \mathrm{m}^{2}$. Even though we did not find a biological cut-point at $47 \mu \mathrm{m}^{2}$, the latter could be used as the cut-point between scores 1 and 2, because there is evidence of the significance of that cut-point in breast cancer (Kronqvist et al., 1998).

The obvious differences and the lack of further cut-points can be explained by the characteristics of breast cancer in Nigeria. Significantly different tumour cell populations, clones, with dissimilar biology, exist in highly proliferating advanced breast cancers. These different clones may have different p53 status, DNA ploidy, proliferation rates and nuclear morphology (Friedrich et al.,1997). Our methodology involved measurements from the most cellular or the most proliferating areas. It is possible that the sampling technique provided a bias towards a single clone measurement. Different sampling rule in Nigerian materials could potentially provide better prognostic value (and potentially also lower thresholds).

\section{REFERENCES}

Aaltomaa S, Lipponen P, Eskelinen M, Alhava E, Syrjänen K (1991). Nuclear morphometry and mitotic indexes as prognostic factors in breast cancer. Eur J Surg 157:319-24.

Aaltomaa S, Lipponen P, Eskelinen M, Kosma VM, Marin S, Alhava E, Syrjänen K (1993). Comparison of classic and quantitative prognostic factors in hormone receptor-positive and hormone receptor-negative female breast cancer. Am J Surg 165:307-11.

Baak JPA, van Dop H, Kurver PH, Herman J (1985). The value of morphometry to classic prognosticators in breast cancer. Cancer 56:374-82.

Baak JPA (1992). Manual of quantitative pathology in cancer diagnosis and prognosis. Springer-Verlag: Berlin, 158.

Baak JP, van Diest PJ, Benraadt T, Matze-Cok E, Brugghe J, Schurmans LT, Littooy JJ (1993). The Multi-center Morphometric Mammary Carcinoma Project (MMMCP) in the Netherlands: value of morphometrically assessed proliferation and differentiation. J Cell Biochem Suppl 179:220-5.

Bloom HJG, Richardson W (1957). Histological grading and prognosis in breast cancer. Br J Cancer 11:359-77.

Chiusa I, Margaria E, Pich A (2000). Nuclear morphometry in male breast carcinoma: associations with cell proliferative activity, oncogene expression, DNA content and prognosis. Int J Cancer 89(6): 494-9.

Cutler SJ, Ederer F (1958). Maximum utilisation of the life tables method in analysing survival. J Chron Dis 8:699-712.

Friedrich K, Dimmer V, Haroske G, Meyer W, Theissig F, Kunze KD (1997). Correlation between p53 status, DNA ploidy, proliferation rate and nuclear morphology in breast cancer. An image cytometric study. Anal Cell Pathol 15(2):85-97.

Glökner S, Lehmann U, Willie N, Kleeberger W, Langer F, Kreipe H (2001). Amplification of growth regulatory genes in intraductal breast cancer is associated with higher nuclear grade but not with the progression to invasiveness. Lab Invest 81: 565-71.

Ihekwaba FN (1992). Breast cancer in Nigerian women. Br J Surg 79:771-5.

Ikpatt OFR, Kuopio T, Collan Y (2001). Histology of Nigerian breast cancer. Pathologica, in press.

Jalava P, Kronqvist P, Smrzova B, Juntti-Patinen L, Kuopio T, Collan YU (2001). Nuclear volume and breast cancer prognosis. Anticancer Res 21(1B):727-32. 
Kronqvist P, Kuopio T, Tamm U, Horvath C, Collan Y (1997). The reproducibility of nuclear morphometric measurements in invasive breast carcinoma. Anal Cell Pathol 15:47-59.

Kronqvist P, Kuopio T, Collan Y (1998). Morphometric grading of invasive ductal breast cancer: Thresholds for nuclear grade. Br J Cancer 78(6):800-5.

Kronqvist P, Kuopio T, Collan Y (1998). Morphometric grading of invasive ductal breast cancer: Thresholds for mitotic counts. Human Pathol 29:1462-8.

Ladekarl M, Söensen FB (1993). Quantitative histopathological variables in in-situ and invasive ductal and lobular carcinomas of the breast. APMS 101:895-903.

Oluwole SF, Fadiran OA, Odesanmi WO (1987). Diseases of breast in Nigeria. Br J Surg 74: 582-585.

Parada D, Farias RM, Garcia-Tamayo J (1987). Morphometric analysis of nuclear variations in normal and neoplastic mammary ductal cells. Inv Clin 40(4):233-44.
Ruiz A, Almenar S, Callaghan RC, Hombart-Bosch A (1999). Benign, preinvasive and invasive ductal breast lesions. A comparative study with quantitative techniques: morphometry, image- and flow cytometry. Pathol Res Pract 195(11): 741-6.

Skjorten F, Kaaresen R, Jacobsen U, Skaane P, Amlie E (1991). Nuclear morphometry of benign and malignant breast lesions. Eur J Surg Oncol 17(4):350-3.

Tahlan A, Nijhawan R, Joshi K (2000). Grading of ductal breast carcinoma by cytomorphology and image morphometry with histologic correlation. Anal Quant Cytol Histol 22(3):1933-8.

Tan PH, Goh BB, Chiang G, Bay BH (2001). Correlation of nuclear morphometry with pathological parameters in ductal carcinoma insitu of the breast. Mod Pathol 14(10):937-4.

WHO (1981). Histological typing of breast tumours. In: International Histological Classification of Tumours, $2^{\text {nd }}$ eds. Geneva: World Health Organisation. 